1978, it took David Jewitt and Jane Luu until 1992, searching with modern instruments, to discover the next body in the Kuiper Belt - a classic case of finding a needle in a haystack. Now we are overwhelmed with TNOs.

The story is well told in Is Pluto a Planet? by David Weintraub, which provides a readable historical account of our knowledge of the Solar System and the concept of what has been considered to be a planet. Fashions have changed with time, and the number of planets has ranged from 6 to 24 . Specialists will note that the author passes over the questionable acquisition by Johannes Kepler of Tycho Brahe's data, which Kepler himself admitted to "usurping”. And Uranus was discovered after a careful search of the heavens by William Herschel, arguably not by accident, but it was probably inevitable. I also found no mention of Burney, who now forms part of the mythology.

A concluding appendix gives a useful discussion of the properties of Pluto and Charon, preceded by the views of various astronomers and planetary specialists on what should constitute a planet. As always, these reveal as much about the commentator as the problem. I found the most perceptive was from Brian Marsden: "It has rarely been scientifically useful to use the word [planet] without some qualification."

Towards the end of this interesting book, Weintraub surprisingly concludes, despite the close analogy between the discovery of the asteroid and Kuiper belts, that we should retain Pluto as a planet by using the three physical parameters of orbital characteristics, mass and roundness. Although he admits that "we know that Pluto earned its status as a planet by accident", this suggestion accords Pluto a kind of royal status. The application of his criteria leads him to a total of 24 planets. This number is bound to grow and the classification is too broad to be scientifically or even culturally useful. As The New York Times has remarked, "too many planets numbs the mind".

Trying to define a planet runs into the philosophical difficulty of attempting to classify any set of randomly assembled items. A bewildering array of objects formed in the early solar nebula, including dust, asteroids, Trojans, centaurs, comets, TNOs and our eight planets, ranging from tiny Mercury to mighty Jupiter. All differ from one another in some salient manner, as do the 160 satellites. The key question is how did they form and evolve, not what pigeonhole can they be forced into. So the decision of the International Astronomical Union that there are eight major planets and a host of minor planets seems an appropriate compromise. But even so, qualifying terms, such as ice giants and Earth-like planets, will always be needed. We need, then, to recall the wise words of Confucius: "The beginning of wisdom is to call things by their right names."

Stuart Ross Taylor is in the Department of Earth and Marine Sciences, Australian National University. He is the author of Solar System Evolution.

\title{
The next pandemic
}

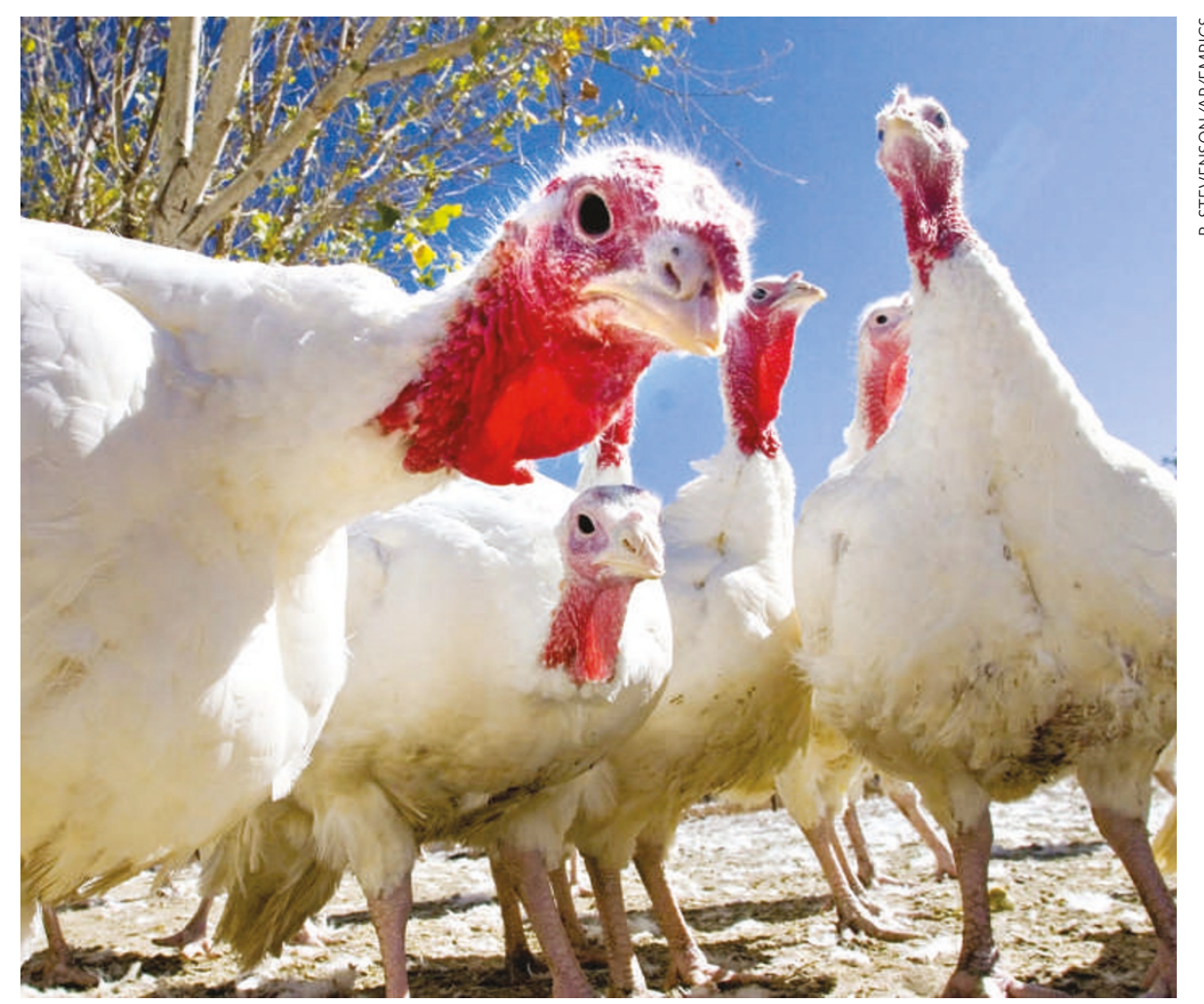

Is this your Christmas dinner? Farmed flocks of poultry could become infected with H5N1 flu.

\section{Bird Flu: A Virus of Our Own Hatching by Michael Greger \\ Lantern Books: 2006. 416 pp. \$30, £21.99}

\section{John Oxford}

I am often kicked around by American authors in books about influenza. How dare a Limey suggest that the Spanish influenza A H1N1 virus arose in a gas-infected, pig-ridden and bird-infected army camp of 100,000 people in France in 1916, when the whole world knows it started in Dorothy's home state, Kansas? But I felt less bruised than usual. Perhaps I am getting used to it.

Bird Flu by Michael Greger pulls and pushes the reader along, and every virologist under the Sun is thrown into the mix. We are projected back to pandemics in 1918, 1957 and 1968. But mostly the searchlight illuminates the current and worrying spread of $\mathrm{H} 5 \mathrm{~N} 1$, the recent theories of pathogenesis, mutation and spread. Greger covers the science rather well, and his descriptions of the polymerase chain reaction, innate immunity, cytokine storms and virus evolution are as clear as crystal. He also provides hundreds of references to burrow into.

But does the book really deliver on its title? It certainly goes to town on the subtitle, burning the bridges that link us to the great international avian reservoir. With the exception of virologists Graeme Laver and Robert Webster, we have only recently realized that influenza A is an avian virus securely seated in the 50 billion ducks, geese and swans that migrate across our planet. Periodically the virus makes the leap to infect humans. But not many of us stroke the feathers of a banded goose, so the virus first moves laterally to domesticated birds and then to their keepers.

The bridge leads to the industrialized chicken industry. I sympathize here. Unbeknown to the UK Department for Environment, Food and Rural Affairs, my wife keeps seven precious chickens at the bottom of the garden. Every autumn they are covered up to avoid the virus-spewing migratory geese who pass overhead. I have slowly cottoned on to why we pour grain into their hungry mouths. We don't like seeing chickens used as fodder, being scalded to death, chopped up alive or, worse, dying of H5N1. There can be no more unpleasant death than a neurological disease that kills a bird in 72 hours. The book is a hydrid, and the trick is to balance a scientific exposition about influenza with a cry from the heart about industrialized farming and how it demeans us. The author notes that "it may take a pandemic with a virus like $\mathrm{H} 5 \mathrm{~N} 1$ before the world realises the true cost of cheap chicken".

Greger is a clever writer. The book is a zinger, not deep like John Barry's The Great Influenza (Viking, 2004; see Nature 429, 345; 2004), but more worldly, broader and more scientific. It is also more global in its approach than most US books, but I suppose it has to be as the United 
States has not yet experienced H5N1.

Fortunately, the world has woken up to the threat of H5N1. The US government has thrown $\$ 9$ billion at the problem, much more than against smallpox and polio combined. Every related research programme in the United States will benefit. The ripples have even reached Britain. There is now an axis of flu research, but will we join it? Yes please!

However, the book fails to confront the question I am asked daily: "Why are you so worried about 151 deaths from H5N1?" Well, go back to 1916, to Etaples in northern France, where a form of flu causing heliotrope cyanosis (a characteristic lavender coloration of the face) with a case fatality of $60 \%$ was beginning to spread. There were 145 cases. At some point in the next two years it mutated to become more infectious and 30 times less virulent. Then it killed 50 million people. Doesn't this ring a nasty bell?

Greger focuses on the chicken industry. His descriptions of how awful it is make for tearful reading. I really mean this. He would do well to fire a few extra missiles at the political class. In 1916 their political antecedents were also preoccupied with war and other vainglorious affairs. They were too busy to read the warnings in The Lancet that a new disease was lurking. Even in Edwardian times, governments could have prepared themselves. The scientists of the day reacted quickly enough; they made pneumonia vaccines, used masks, hygiene and social distancing, and many died in the attempt. Today we are well served in Britain and the rest of the European Union, but many nations in the world deserve better. They will face the next pandemic truly naked and bereft.

I am not as pessimistic as Greger. I like Churchill's attitude: "Give us the tools and we will finish the job." Well, for the first time in our history, we have them, and we will.

John Oxford is at the Centre for Infectious

Diseases, Retroscreen Virology, Queen Mary,

University of London, 327 Mile End Road,

London E1 4NS, UK.

\section{The snowflake man}

\section{Wilson Bentley's photographs of snow crystals strike a chord with us all.}

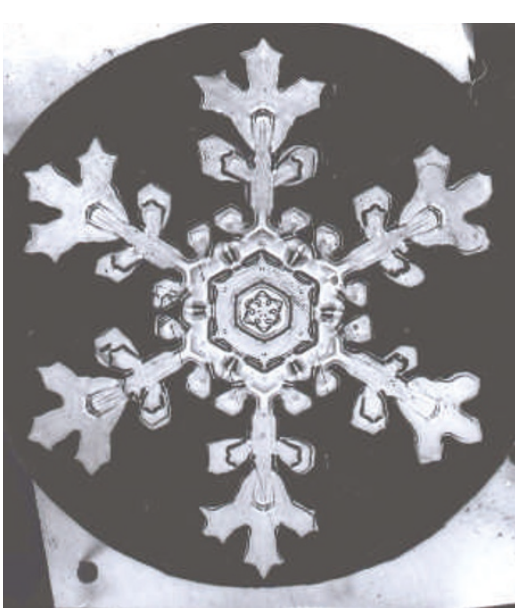

Martin Kemp

Since its debut in Johannes Kepler's book On the Six-Cornered Snowflake in 1611 (see Nature 432, 953; 2004), the snowflake shape has become as familiar as nature's other geometrical designs, such as the spider's web, the honeycomb and mollusc shells. The intricate and remarkably varied structures of snow crystals were shown for the first time in Robert Hooke's Micrographia in 1665.

The most unlikely hero in the later story of snowflake structure is a Vermont farmer with no orthodox scientific credentials, Wilson Bentley (1865-1931). Born into a farming family, the young Bentley developed an intense fascination with the structure of snow. At the age of 20 , using a specially constructed rig of bellows camera and microscope, he took the first photograph of a single snow crystal.

One of the great eccentrics of science, 'Snowflake' Bentley (as he was known in his local community) resided steadfastly in the family farmhouse for his whole life. But this did not stop him publishing a series of wellregarded books and articles in scientific and popular journals.
His 1931 book Snow Crystals, which contains photographs (like that shown on the left) of almost 2,500 crystals, stands alongside Ernst Haeckel's illustrated volumes on the radiolaria as a classic on the geometrical sciences of nature. Bentley's systematic procedures, delicate manual dexterity, incredible patience and tolerance of working in freezing conditions were motivated by a sense of poetic wonder. Some of his enraptured tone is conveyed in a piece he wrote for Harper's Monthly Magazine: "Quick, the first flakes are coming; the couriers of the coming snow storm. Open the skylight, and directly under it place the carefully prepared blackboard, on whose ebony surface the most minute form of frozen beauty may be welcome from cloud-land. The mysteries of the upper air are about to reveal themselves, if our hands are deft and our eyes quick enough." It was Bentley who told the world that no two snowflakes are precisely alike. This variety, we now know, has a number of causes: the construction of the crystals from about $10^{18}$ water molecules; their formation under varying temperatures as they swirl with their cloud; and the unpredictability of the processes of aggregation from one crystal to another.

Bentley also knew that, in contrast to popular belief, most crystals are not wholly symmetrical - it's just that the symmetrical ones are generally selected for illustration.

The complexity of the infinite variations on the hexagonal structure continues to attract serious scientific attention, for example from physicist Kenneth Libbrecht at the California Institute of Technology. Libbrecht's lively website, which includes animated images of crystal growth (www.its.caltech.edu/ atomic/snowcrystals/movies/movies.htm), is both informative and appropriately entertaining for the festive season. The image shown below is from Ken Libbrecht's Field Guide to Snowflakes (Voyageur, 2006).

Mathematically, the snowflake has also been enlisted in the cause of fractals. In 1904 the Swedish mathematician Niels Fabian Helge von Koch published his 'snowflake curve', generated from an equilateral triangle. Each side is trisected and the centre segment replaced by two sides of a smaller equilateral triangle projecting outward. This process is repeated ad infinitum. The total length increases with each step, but the length of each side approaches zero. In this sense it is unlike a snowflake in nature, the lower limit of which is set by the size of a water molecule.

The hexagonal configurations familiar from Christmas lights in streets around the world and glittering on countless Christmas trees testify that the passion shown by these snowflake pioneers is shared by everyone who responds intuitively to the geometry of nature. Perhaps that is all of us.

Martin Kemp is professor of the history of art at the University of Oxford, Oxford OX11PT, UK. His new book, Seen | Unseen, is published by Oxford University Press.

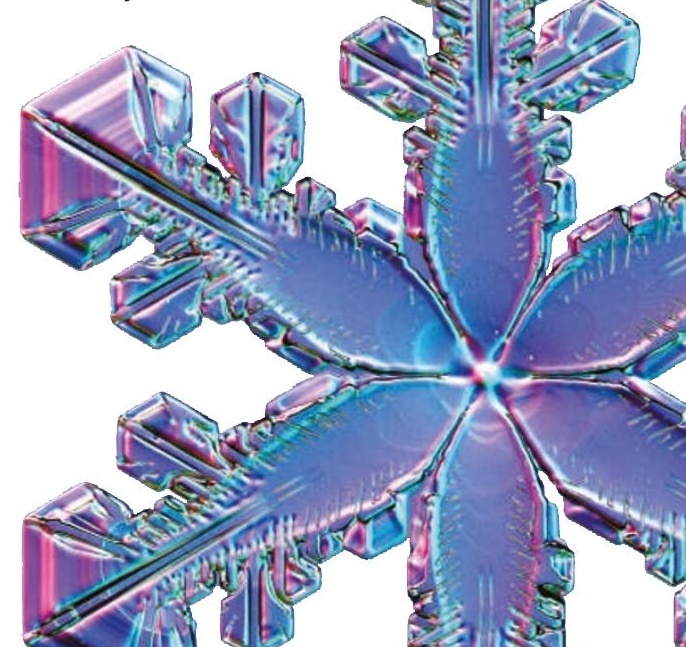

